\title{
Total Core Losses and Dilatometric Properties of Bulk Amorphous Fe-Based Alloys
}

\author{
B. PŁoszaj ${ }^{a}$, M. NABiAŁeK $^{a, *}$, K. BŁoch ${ }^{a}$, B. KoczurkieWicz $^{b}$, \\ A.V. SANDU ${ }^{c, d}$, M.M.A.B. ABDullah ${ }^{d}$, A. KAlwiK ${ }^{e}$ AND B. JEŻ $\dot{Z}^{a}$ \\ ${ }^{a}$ Department of Physics, Faculty of Production Engineering and Materials Technology, \\ Częstochowa University of Technology, Al. Armii Krajowej 19, 42-200 Częstochowa \\ ${ }^{b}$ The Institute of Plastic Working and Safety Engineering, \\ Faculty of Production Engineering and Materials Technology, \\ Częstochowa University of Technology, Al. Armii Krajowej 19, 42-200 Częstochowa \\ ${ }^{c}$ Gheorghe Asachi Technical University of Iasi, Faculty of Materials Science and Engineering, \\ Blvd. D. Mangeron 41, 700050, Iasi, Romania \\ ${ }^{d}$ Center of Excellence Geopolymer\& Green Technology (CEGeoGTech), \\ School of Materials Engineering, Universiti Malaysia Perlis, 01000 Kangar, Perlis, Malaysia \\ ${ }^{e}$ Department of Technology and Automation, \\ Faculty of Mechanical Engineering and Computer Science, \\ Częstochowa University of Technology, Al. Armii Krajowej 19, 42-200 Częstochowa
}

Doi: 10.12693/APhysPolA.138.221

*e-mail: nabialek.marcin@wip.pcz.pl

\begin{abstract}
Research on structure and magnetization losses made for bulk iron-based amorphous alloys are presented. Bulk alloys were made by injection casting in the form of rods with a diameter of $1 \mathrm{~mm}$. Losses on remagnetization was tested after samples solidification. Samples had an amorphous structure. The dilatometric properties of the samples after solidification were also tested. These tests were performed at room temperature in the frequency range from 0 to $1000 \mathrm{~Hz}$. Magnetostriction for this type of material should be close to zero, which results in almost complete removal of the double noise spectrum effect. One of the most important parameters determining the ability to use electrotechnical materials in transformers are losses due to magnetization and the associated effect of magnetostriction. Limiting these two side effects of the magnetization process of magnetic cores impacts environmental protection and economy.
\end{abstract}

topics: bulk amorphous alloys, injection casting, total loss cores, additional losses, magnetostriction

\section{Introduction}

Bulk amorphous materials belong to new group of functional materials [1-6]. Especially large interest is given to Fe-based alloys. These materials show soft magnetic and mechanical properties [7-10], and are used as cores inside low loss transformers because of their high saturation magnetization and low remagnetization losses. Losses for remagnetization are an important parameter which is measure of the surface area of the hysteresis loop. Usually these losses are determined by dynamic measurement in certain frequencies. Unique structure visible as lack of long range ordering inside amorphous materials is considered as the factor responsible for low losses. In amorphous materials total losses $\left(P_{C}\right)$ are related with hysteresis loop surface $\left(P_{\text {his }}\right)$, losses for eddy currents $\left(P_{\mathrm{cl}}\right)$ and so-called additional losses $\left(P_{\text {exc }}\right)[11,12]$, namely

$$
P_{t}=P_{\text {his }}+P_{\mathrm{cl}}+P_{\text {exc }} \text {. }
$$

Additional losses might be approximated by the following formula:

$$
P_{\text {exc }}=8.76 \sqrt{\sigma G S V_{0}} B_{\text {peak }}^{3 / 2} f^{3 / 2},
$$

where $\sigma$ is electrical conductivity, $G$ is dimensionless factor, $S$ is the cross-section area of the sample, $V_{0}$ is a constant associated with the impact of braking centers of the domain walls, $B_{\text {peak }}$ the maximum value of the induction, and $f$ is frequency.

Lack of crystal structure is the reason for almost reduced phenomenon of magnetrostriction in amorphous materials [13]. Magnetostriction might be measured among others by analysing the changes of sample dimension for a given frequency value. Elimination of magnetostriction results is treated as a positive effect for environmental protection and is considered as an economical factor.

In this paper the dynamic hysteresis loops for $\mathrm{Fe}_{70} \mathrm{Y}_{5} \mathrm{Nb}_{4} \mathrm{Mo}_{1} \mathrm{~B}_{20}$ alloy in rod shape with $1 \mathrm{~mm}$ diameter in frequency range from 50 to $1000 \mathrm{~Hz}$ were examined. On the basis of curves generated by 
Ferrometer, the total losses for samples in the state after solidification were calculated. Furthermore, the magnetostriction was analyzed for a frequency value of $50 \mathrm{~Hz}$ and $100 \mathrm{~Hz}$.

\section{Materials and methods}

Polycrystalline $\mathrm{Fe}_{70} \mathrm{Y}_{5} \mathrm{Nb}_{4} \mathrm{Mo}_{1} \mathrm{~B}_{20}$ alloy was made in arc furnace from components for which purity exceedes $99.9 \%$. Solidification process was conducted in a neutral gas environment $(300 \mathrm{hPa}$ argon pressure was used). Batch was melted with the use of nonconsumable tungsten electrode. Temperature of plasma arc is controlled by current flowing through electrode (180-380 A). To obtain homogenic alloy structure, batch melting procedure was done for both side repeatedly. Every process of solidification was preceded by remelting titanium getter. Obtained 5 gram ingot was divided into smaller pieces, which then were treated mechanically and with ultrasonic washer. Rapid cooled alloy was produced with the injection method. Batch was placed in quartz crucible inside copper coil. Alloy was melted by the use of eddy currents with constant current flowing through the coil (10 A). Liquid alloy was pressed into argon pressure to water cooled copper form. Rods with the diameter of $1 \mathrm{~mm}$ and length of $20 \mathrm{~mm}$ were made.

Structure of the obtained material was analyzed by the use of X-ray diffraction. X-ray machine branded by Bruker model Advanced 8 equipped with semiconductor count and $\mathrm{CuK}_{\alpha}$ lamp was used. Measurements were done in the range $30^{\circ}-100^{\circ}$ of angle two theta.

Magnetic dynamic hysteresis loop was measured by transformer method with the usage of ferrometer. Obtained rods were placed in yokes made of super permalloy. Measurements were done in the range $50-1000 \mathrm{~Hz}$ under room temperature.

\section{Results}

The results of X-ray diffraction for produced alloy are presented in Fig. 1.

Measured diffractometer is typical as for materials with amorphous structure. Only one wide maximum is visible that is related to X-ray radiation dissipated on chaotically placed atoms in sample volume. In Fig. 2 dynamic magnetic hysteresis loops for analyzed alloy are placed. In low current magnetic fields for amorphous alloys showing so called soft magnetic properties, irreversible magnetization process occurs. In fact, this results with creation of the hysteresis loop. Along with an increase of magnetic field frequency loop surface area raises. In Fig. 3 the total losses obtained for analyzed alloy are presented.

In the case of amorphous alloys, the main components of losses come from magnetic hysteresis loop. The eddy current component has a smaller contribution to losses due to the relatively small

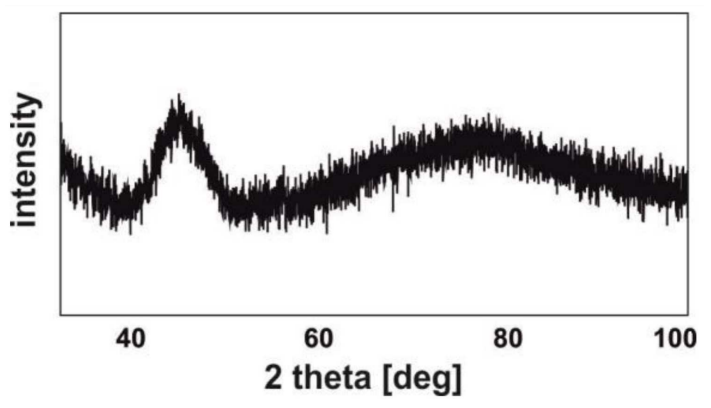

Fig. 1. X-ray diffractometer

$\mathrm{Fe}_{70} \mathrm{Y}_{5} \mathrm{Nb}_{4} \mathrm{Mo}_{1} \mathrm{~B}_{20}$ alloy in rod shape.

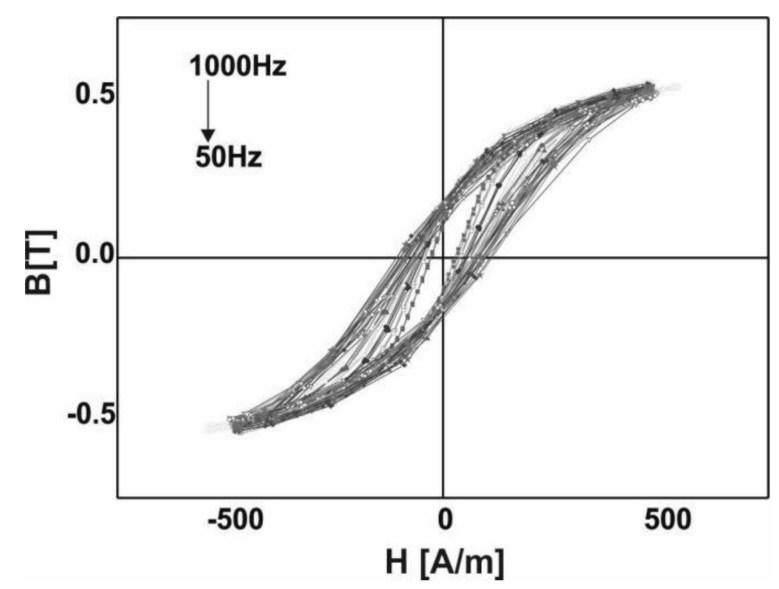

Fig. 2. Dynamic magnetic hysteresis loops measured for produced alloys in $50-1000 \mathrm{~Hz}$ frequency range magnetizing field.

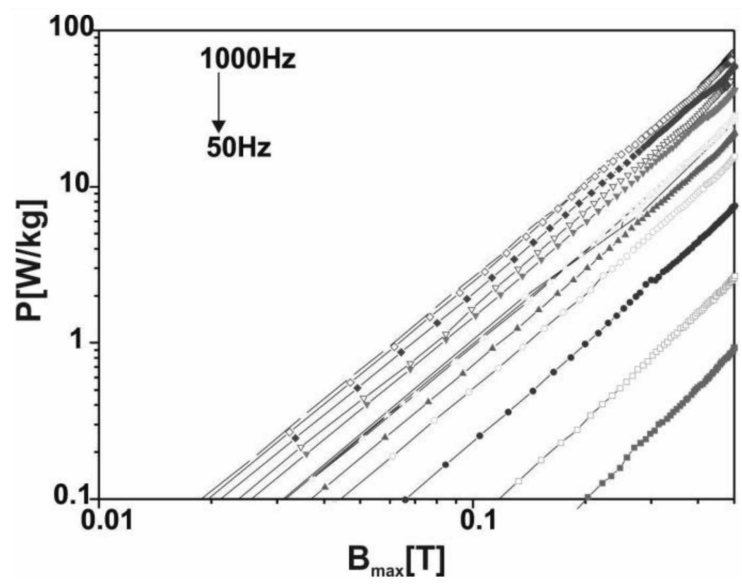

Fig. 3. Losses for remagnetization in function of maximum induction for produced alloys in 50$1000 \mathrm{~Hz}$ frequency of the magnetizing field.

value of the cross-section of the samples. Based on the analysis of the curves in Fig. 4, the additional losses were determined for the maximum induction value $B_{\max }=0.3 \mathrm{~T}$.

Losses on remagnetization increase with the square of the frequency [13]. Theoretically, losses are a linear function of the frequency square. 


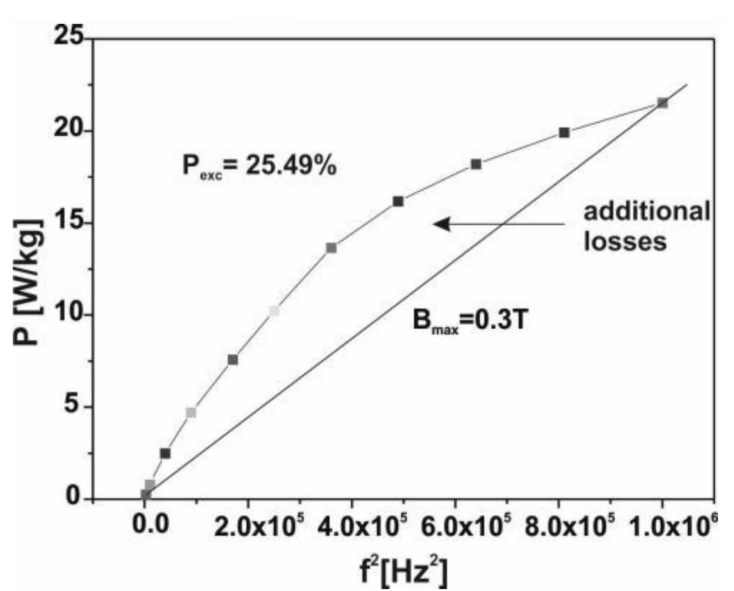

Fig. 4. Additional losses determined for $\mathrm{Fe}_{70} \mathrm{Y}_{5} \mathrm{Nb}_{4} \mathrm{Mo}_{1} \mathrm{~B}_{20}$ alloy for $B_{\max }=0.3 \mathrm{~T}$.

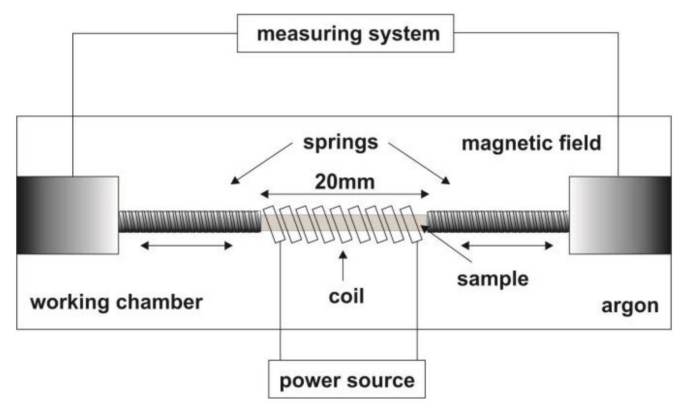

Fig. 5. Scheme of the system for measuring the magnetostricion.

In practice, however, the composition fluctuations affect on local changes in alloy viscosity and cause delays in the magnetization process. This, in turn, generates additional losses. For the analyzed alloy, the component represents $25 \%$ of the total losses. This means that such factor has a significant impact on the performance of iron-based amorphous alloys. Figure 5 shows a diagram of the system in which magnetostriction was measured. the measurement was carried out for the demagnetized alloy and for the applied constant magnetic field ensuring magnetization to ferromagnetic saturation $(0.5 \mathrm{~T})$. The dilatometer has an accuracy of $10^{-9} \mathrm{~m}$. the lack of registered change in the sample length despite of the applied magnetic field, indicates almost zero alloy magnetostriction.

\section{Conclusions}

The aim of the study was to investigate the losses on remagnetization for the bulk amorphous $\mathrm{Fe}_{70} \mathrm{Y}_{5} \mathrm{Nb}_{4} \mathrm{Mo}_{1} \mathrm{~B}_{20}$ alloy. The tested alloy has losses comparable to conventional Fe- $\mathrm{Si}$ sheets [14]. Additional losses for the produced material in a onestage process caused by rapid cooling are about $25 \%$ of the total losses. As a result of dilatometric tests for the sensor with an accuracy of $1 \mathrm{~nm}$ and the sample with a length of $20 \mathrm{~mm}$, no change in dimension was observed. This means that the tested material based on Fe is almost zero magnetostrictive material. The tested alloy, due to its exhibiting parameters, can be an alternative to the construction of low loss, environmentally friendly transformers.

\section{References}

[1] K. Pawlik, P. Pawlik, J.J. Wysłocki, W. Kaszuwara, J. Alloys Compd. 536S, S348 (2012).

[2] S. Hasani, P. Rezaei-Shahreza, A. Seifoddini, M. Hakimi, J. Non-Crystal. Solids 497, 40 (2018).

[3] Y. Geng, Y. Wang, Z. Wang, J. Qiang, H. Wang, C. Dong, O. Tegus, Mater. Des. 106, 69 (2016).

[4] P. Rezaei-Shahreza, A. Seifoddini, S. Hasani, J. Alloys Compd. 738, 197 (2018).

[5] S. Hasani, P. Rezaei-Shahreza, A. Seifoddini, Metall. Mater. Trans. A 50, 63 (2019).

[6] K. Pawlik, P. Pawlik, W. Kaszuwara, J.J. Wysłocki, Acta Phys. Pol. A 126, 186 (2014).

[7] M.E. Mchenry, M. A. Willard, D.E. Laughlin, Prog. Mater. Sci. 44, 291-433 (1999).

[8] M. Nabiałek, K. Jeż, Revista de Chimie 69, 1593 (2018).

[9] Z. Jaafari, A Seifoddini, S Hasani, Metall. Mater. Trans. 50, 2875 (2019).

[10] S. Hasani, M Ansarinia, A Seifoddini, Mater. Sci. Technol. 35, 865 (2019).

[11] E. Barbisio, F. Fiorillo, C. Ragusa, IEEE Trans. Magn. 40, 1810 (2004).

[12] R. Piccin, P. Tiberto, H. Chiriac, M. Baricco, J. Magn. Magn. Mater. 320, 806 (2008).

[13] Y. Jin, Y. Chao, F. Liu, J. Wang, M. Sun, J. Magn. Magn. Mater. 468, 181 (2018).

[14] I. Ibarrondo, J. Degauque, Vacuum 53, 75 (1999). 